[0212-7199 (2004) 21: 12; pp 590-592] ANALES DE MEDICINA INTERNA Copyright (C) 2004 ARAN EDICIONES, S.L.

AN. MED. INTERna (Madrid) Vol. 21, N. ${ }^{\circ} 12$, pp. 590-592, 2004

\title{
Fiebre y dolor abdominal. Un caso de fiebre mediterránea familiar
}

\author{
R. PERELLÓ CARBONELL, A. SMITHSON AMAT ${ }^{1}$, A. SUPERVÍA CAPARRÓS, \\ L. ARENILLAS ROCHA ${ }^{1}$, V. TORRENTE SEGARRA, E. SKAF PETERS
}

Servicio de Urgencias. Hospital del Mar. Barcelona. ${ }^{\text {SServicio de Enfermedades }}$

Infecciosas. Hospital Clínico y Provincial. Barcelona

\begin{abstract}
FEVER AND ABDOMINAL PAIN. A CASE OF FAMILIAL MEDITERRANEAN FEVER
\end{abstract}

\section{RESUMEN}

La fiebre mediterránea familiar (FMF) es una enfermedad hereditaria, transmitida de forma autosómica recesiva, caracterizada por episodios recurrentes y breves de fiebre y dolor secundario a serositis. El dolor suele localizarse en abdomen simulando a veces un abdomen agudo, y en tórax en forma de dolor pleurítico. La complicación más grave de la FMF es el desarrollo de amiloidosis, siendo ésta la principal causa de muerte. Siendo la FMF una enfermedad que afecta a determinados grupos étnicos de la cuenca mediterránea y debido a su escasa prevalencia en nuestro medio, presentamos el caso de un paciente varón de 30 años que presentaba dolor abdominal y torácico recurrentes cuyo diagnóstico final fue el de FMF. Se hace hincapié en la dificultad diagnóstica de la misma.

PALABRAS CLAVE: Fiebre mediterránea familiar. Dolor abdominal. Amiloidosis.

\begin{abstract}
Familial mediterranean fever $(F M F)$ is an hereditary disease transmitted in an autosomal recesive way and characterized by recurrent and brief episodies of fever and pain secondary to serositis. The pain is usually located in abdomen simulating an acute abdomen, and in thorax in the form of pleuritic pain. The most severe complication of the FMF is the development of amyloidosis being the main cause of death. This illness affects an specific ethnic group of the mediterranean area, but the prevalence in our area is low. We present the case of a 30 years old man with recurrent thoracic and abdominal pain, whose final diagnostic was FMF. Insisting on the difficulty that it was recognize this proper illness.
\end{abstract}

KEY WORDS: Familial mediterranean fever. Abdominal pain. Amiloidosis.

Perelló Carbonell R, Smithson Amat A, Supervía Caparrós A, Arenillas Rocha L, Torrente Segarra V, Skaf Peters E. Fiebre y dolor abdominal. Un caso de fiebre mediterránea familiar. An Med Interna (Madrid) 2004; 21: 590-592.

\section{INTRODUCCIÓN}

La fiebre mediterranea familiar (FMF) es una enfermedad hereditaria autosómica recesiva que se caracteriza por episodios recurrentes de fiebre y dolor secundario a serositis. Los episodios suelen ser de corta duración y el dolor suele localizarse en abdomen, simulando a veces un abdomen agudo, y en tórax en forma de dolor pleurítico. La complicación más grave de la FMF es el desarrollo de amiloidosis, siendo la principal causa de muerte en estos pacientes. La FMF afecta a determinados grupos étnicos de la cuenca mediterránea: judíos sefarditas, armenios, turcos, norteafricanos, árabes y menos comúnmente a griegos e italianos. En el norte de Europa y en Estados Unidos se han descrito casos en judíos asquenazíes, siendo excepcional en otras poblaciones. En nuestro país se han identificado 82 casos entre los judíos conversos de Mallorca, y se han diagnosticado casos aislados en Gerona, Toledo, Madrid y zonas de Andalucía (1).
Debido a la escasa prevalencia de la FMF en nuestro medio, su diagnóstico requiere de una alta sospecha clínica, sobre todo en pacientes que acuden a los Servicios de Urgencias por fiebre y dolor abdominal. Por ello, creemos de interés presentar el caso de un paciente que presentaba crisis de dolor abdominal y torácico recurrentes, cuyo diagnóstico final fue el de FMF.

\section{CASO APORTADO}

Varón de 30 años, sin hábitos tóxicos, que consulta por fiebre y dolor abdominal y torácico. El paciente refería episodios recurrentes similares en los últimos cinco años. En una ocasión se diagnosticó de probable abdomen agudo, habiendo estado a punto de ser laparotomizado. El episodio actual se presenta con fiebre de $39,5^{\circ} \mathrm{C}$, dolor abdominal y dolor pleurítico en hemitórax derecho de 24 horas de evolución. La exploración mostró un abdomen doloroso, sobre todo en fosa iliaca derecha, con signos de irritación peritoneal. En la ana-

Trabajo aceptado: 25 de mayo de 2004

Correspondencia: R. Perelló Carbonell. Sevicio de Urgencias. Hospital del Mar. Passeig Marítim, 25-29. 08003 Barcelona. e-mail: rperello@imas.imim.es 
lítica destacaba PCR $25 \mathrm{mg} / \mathrm{dl}$ y leucocitos 18.109/ml La radiografía de tórax fue normal y una ecografía abdominal no evidenció datos sugestivos de apendicitis aguda. Se inició tratamiento analgésico con remisión del cuadro en 24 horas, siendo dado de alta. Posteriormente se realizó estudio ambulatorio con TC abdominal y fibrocolonoscopia que fueron normales. Ante la remisión total de la clínica, los antecedentes de episodios recurrentes y la negatividad de las pruebas practicadas se orientó como una posible FMF, procediéndose a estudio genético. Este mostró dos mutaciones en el gen MEFV: una en el exón 2, detectándose la sustitución del nucleótido guanina por citosina en la primera posición del triplete 148, dando lugar al cambio de aminoácido glutámico por glutamina. Dicha mutuación recibe el nombre de E148Q, y se detectó en un solo alelo, por lo que el paciente es heterozigoto para esta mutuación. Se detectó una segunda mutuación en el exón 10, que consistía en la sustitución del nucleótido guanina por adenina en la tercera posición del triplete 694, dando lugar al cambio de aminoácido metionina por isoleucina. Dicha mutuación recibe el nombre de M694I y también se detectó en un solo alelo, por lo que el paciente es también heterozigoto para esta mutuación. Ambas mutaciones están descritas en la FMF. Asimismo se realizó un estudio del exón 3 de la proteina sérica del amiloide SAA-1, que mostró un genotipo alfa/beta, considerado de bajo riesgo para el desarrollo de amiloidosis. Se inició tratamiento con colchicina a dosis de $1 \mathrm{mg} /$ día con buena evolución posterior y desaparición paulatina de las crisis.

\section{DISCUSIÓN}

La SMF es una enfermedad hereditaria autosómica recesiva, cuyo gen fue identificado en 1992 en el brazo corto del cromosoma 16, denominándose MEFV (2). Posteriormente fue clonado y caracterizado en 1997 por dos grupos internacionales diferentes: el Consorcio francés/israelí y el Consorcio internacional. La proteína resultante de la trancripción de dicho gen se denominó mianserina por el primer grupo, nombre derivado del término latino Mare Nostrum, debido a la agrupación de la enfermedad en la cuenca mediterránea. El segundo grupo la denominó pirina por su relación con la pirexia (1).

La FMF afecta a determinados grupos étnicos, habiéndose descrito casos esporádicos en otras poblaciones. Su diagnóstico en ausencia de antecedentes familiares suele ser difícil y precisa de un alto grado de sospecha. Éste se basa en la peridiocidad de los cuadros de dolor abdominal y fiebre, la presencia de serositis en la TC abdominal o de derrame pleural en la radiografía de tórax y en la respuesta al tratamiento con colchicina. El test de provocación con metaraminol se ha empleado como prueba diagnóstica, pero sus riesgos cardíacos hace que no sea usada de forma rutinaria (3). Por otro lado, la elevación de dopamina betahidroxilasa en el suero de los pacientes con FMF no ha sido confirmada (4). Hoy en día, el diagnóstico definitivo se realiza con la demostración de determinadas mutaciones genéticas.

Clínicamente, la FMF se caracteriza por episodios recurrentes y breves de fiebre y dolor con inflamación de una o varias serosas (peritoneo, pleura, pericardio, sinovial o túnica vaginal del testículo). Como consecuencia, se producen cuadros de dolor abdominal recurrente y/o de dolor pleurítico raramenete complicado con hemorragia, infiltrados o infarto pulmonar (5). Se han descrito casos de pericarditis recidivantes, alguno de los cuáles ha precisado pericardiocentésis, y algún episodio de taponamiento cardíaco (6). También produce episodios prolongados de fiebre y mialgias (7). La afectación escrotal suele ser mayoritariamente unilateral, acompa- ñándose de dolor agudo (8), existiendo algún caso de presentación recidivante (9).

El cuadro de dolor abdominal agudo, que muchas veces simula un abdomen agudo, requiere un amplio diagnóstico diferencial entre afecciones quirúrgicas y no quirúrgicas. Las principales entidades con las que puede ser confundida se describen en la tabla I. También deben descartarse los procesos que cursan con fiebres periódicas, como la hipergammaglobulinemia D. Muchas de estas enfermedades pueden ser descartadas con la realización de un interrogatorio y exploración física completas y el resultado de las pruebas complementarias.

\section{TABLA I}

\section{DIAGNÓSTICO DIFERENCIAL DE LA FMF}

\begin{tabular}{l} 
Procesos quirúrgicos \\
Apendicitis aguda \\
Perforación intestinal \\
Colecistitis aguda \\
Procesos no quirúrgicos \\
Brote ulceroso \\
Pancreatitis recurrente \\
Dolor abdominal secundario a la diabetes mellitus descompensada \\
Crisis hemolítica \\
Porfiria aguda intermitente \\
Intoxicación por plomo \\
Insuficiencia suprarrenal aguda \\
Edema angioneurótico \\
Lupus eritematoso sistémico \\
Migraña abdominal \\
Artritis crónica juvenil \\
\hline
\end{tabular}

En nuestro paciente, dado el carácter recurrente de la clínica, la negatividad de las pruebas de imagen y fibrocolonoscopia, y la ausencia de antecedentes epidemiológicos que pudieran presuponer una intoxicación por plomo, hicieron que se solicitara un estudio genético en busca de mutaciones propias de FMF. La ausencia de signos de serositis en la TC abdominal podría explicarse debido a que ésta se realizó de forma ambulatoria en un periodo intercrisis.

El tratamiento de la SMF se basa en la administración de colchicina a dosis que varían entre 1-2 mg/día por vía oral. En casos refractarios, la administración de colchicina semanal endovenosa junto con la administración oral parece ser una terapia efectiva y segura (10). La administración profiláctica de colchicina ha demostrado la disminución de los brotes inflamatorios así como la prevención del desarrollo de amiloidosis.

Queremos hacer énfasis en la dificultad del diagnóstico de esta entidad, sobre todo ante un paciente que se presenta con clínica de abdomen agudo y fiebre, en ausencia de antecedentes familiares, requiriendo un amplio diagnóstico diferencial que incluye enfermedades quirúrgicas y no quirúrgicas. El diagnóstico de FMF tiene importantes implicaciones ya que puede evitar laparotomias innecesáreas. Además, el tratamiento con colchicina permite no sólo controlar los brotes sino disminuir de forma drástica la progresión amiloidótica, principal causa de mortalidad asociada a dicha enfermedad. 


\section{Bibliografía}

1. Buades Reines J, Aguirre Errasti C. Fiebre mediterránea familiar. Med Clin (Barc) 2001; 117: 142-146.

2. Pras E, Aksentjevitch I, Gruberg L, Balow J, Prosen L, Dean et al. Mapping of a gene causing familial mediterranean fever to the short arm of chromosome 16. N Eng J Med 1992;326:1507-1513.

3. Buades J, Bassa A, Altés J, Vicens JM. The metaraminol tests adverse cardiac effects. Ann Intern Med 1989; 111: 259-260.

4. Barakast MH, Guma KA, Malhas LN, El-Sobki NI, Moussa MA, Fenech FF. Plasma dopamine beta hydroylase: rapid diagnostic test for recurrent hereditary polyserositis. Lancet 1988; 2: 1280-1283.

5. Livneh A, Langevitz P, Pras M. Pulmonary associations in familial Mediterranean fever. Curr Opin Pulm Med 1999; 5: 326-331.

6. Zimand S, Tauber T, Hegesch T, Aladjem M. Familial Mediterranean fever pressenting with massive cardiac tamponade. Clin Exp Rheumatol 1994; 12: 67-69.

7. Odabas AR, Cetinkaya R, Selcuk Y, Kaya H. Severe and prologed febrile myalgia in familial Mediterranean fever. Scand J Rheumatol 2000; 29: 394-395.

8. Majeed HA, Ghanddour K, Shabin HM. The acute scrotum in Arab children with familial Mediterranean fever. Pediatr Surg Int 2000; 16: 72-74.

9. Ferrero Doria R, Guzmán Martínez-Valls P, López Alba J, Tomás Ros M, Rico Galiano JL, Rodriguez de Ledesma JM, Fontana Compiano LO. Hidrocele recidivante en un paciente con fiebre mediterránea familiar. Arch Esp Uro 1997; 50: 800-801.

10. Lidar M, Kedem R, Langevitz P, Pras M, Livneh A. Intavenous colchicine for treatment of pacients with familial Mediterranean fever unresponsive to oral colchicine. J Rheumatol 2003; 30: 2620-2623. 